\title{
O ensino da álgebra em uma turma do oitavo ano de uma escola pública de São Mateus - ES
}

\author{
Algebra teaching in an eighth grade class at a public school in São \\ Mateus - ES \\ Valdinei Cezar Cardoso \\ Caroline Alves Santiago \\ Roberta dos Santos Ribeiro
}

Resumo: O presente trabalho, visa investigar possíveis contribuições da utilização de dois jogos educativos em aulas de matemática, para ensinar as operações de adição, subtração e multiplicação de polinômios para uma turma do $8^{\circ}$ ano do Ensino Fundamental, que tiveram um papel investigativo, mostrando que os alunos possuem dificuldades de interpretação e portanto, dificuldades na passagem da linguagem natural para a algébrica e geométrica, bem como em conceitos importantes como os de perímetro e área. Por este motivo, se torna importante metodologias de ensino que visam enfatizar a interpretação de problemas e a contextualização desse conteúdo à realidade dos alunos, visto que alguns deles não conseguem visualizar a utilidade desses conceitos no dia a dia.

Palavras chave: Álgebra. Aprendizagem. Jogos educativos.

Abstract: The present work aims to investigate possible contributions of the use of two educational games in the mathematics classes, to teach the operations of addition, subtraction and multiplication of polynomials for a class 8th year of Elementary School, wich had an investigative role, showing that students have difficulties in interpretation and therefore, difficulties in the transition from natural to algebraic and geometric language as well as in important concepts such as perimeter and area. For this reason, teaching methodologies that aim to emphasize the interpretation of problems and the contextualization of this content to the students'reality become important, since some of them are unable to visualize the usefulness of these concepts on a daily basis. Keywords: Algebra. Learning. Educational games.

\section{Introdução}

Grande parte dos estudantes apresentam dificuldades na aprendizagem de matemática. O fato de ser uma disciplina que envolve representações simbólicas, linguagem algébrica formal, execução de vários cálculos e demanda raciocínio pode levar a essas concepções.

O presente trabalho, visa investigar possíveis contribuições da utilização de dois jogos educativos em aulas de matemática, para ensinar as operações de adição, subtração e multiplicação de polinômios. Os sujeitos desta pesquisa são estudantes do $8^{\circ}$ ano do Ensino Fundamental de uma escola pública 
municipal de São Mateus - ES, que foram escolhidos porque apresentavam um baixo rendimento na disciplina de matemática, por este motivo participavam de aulas complementares oferecidas dentro do Programa Institucional de Bolsas de Iniciação à Docência - Pibid em que a terceira autora deste trabalho atuava. Assim, nos direcionamos em contribuir para o aprendizado desses sujeitos analisando suas dificuldades quanto ao estudo de álgebra.

Durante a atuação das últimas autoras deste trabalho em uma escola do ensino básico, como parte dos requisitos para concluir a disciplina Prática como Componente Curricular I - PCCl, do curso de Licenciatura em Matemática da Universidade Federal do Espírito Santo, Campus São Mateus, notamos que as operações com polinômios são de difícil compreensão para muitos estudantes. Isso acontece principalmente quando há a passagem da linguagem natural ${ }^{1}$ para a linguagem algébrica (GIL, 2008; VELOSO; FERREIRA, 2010).

Gil (2008), pontua que as primeiras noções algébricas são dadas a partir do $7^{\circ}$ ano do Ensino Fundamental, porém é no $8^{\circ}$ ano que este conteúdo é visto com mais profundidade e os alunos se deparam com algo novo, diferente do que estavam acostumados.

Da mesma forma, Portes e Alves (2014, p. 2) discorrem sobre as dificuldades na aprendizagem de álgebra dos alunos do $8^{\circ}$ ano. Para eles, depois de algum tempo no ensino de matemática, "é possível perceber que os estudantes do $8^{\circ}$ ano do ensino fundamental encontram muitas dificuldades no aprendizado de álgebra, principalmente nas operações com polinômios". Os autores destacam que para os alunos, é difícil associar números e letras, pois eles "não entendem o significado e qual é a utilidade prática de tal conhecimento".

Deve-se também fazer reflexões de como o conteúdo é ensinado, na maioria das vezes, o docente tem o livro didático como o único recurso na sala de aula. A forma como o professor desenvolve os procedimentos algébricos, também pode contribuir para o não entendimento dos alunos, fazendo com que tenham receio em relação a matemática. Por este motivo, o fato de a álgebra

\footnotetext{
${ }^{1} \mathrm{~A}$ linguagem que utilizamos no cotidiano.
} 
ser uma área da matemática que exige formalismo em sua linguagem, este não deve ser o único fator a ser considerado (GIL, 2008).

A Base Nacional Comum Curricular de 2017, aponta que o estudo da álgebra tem por finalidade o desenvolvimento do pensamento algébrico

que é essencial para utilizar modelos matemáticos na compreensão, representação e análise de relações quantitativas de grandezas e, também, de situações e estruturas matemáticas, fazendo uso de letras e outros símbolos (BRASIL, 2017, p. 270).

Assim, verifica-se a importância do desenvolvimento de uma base sólida no Ensino Fundamental pois acompanhará o estudante nas próximas etapas escolares além de ser fundamental a sua aplicação em diversas situações do cotidiano, na solução de problemas. Nesse contexto, Costa et al. (2016), afirmam que as concepções algébricas sustentam conhecimentos mais abstratos, colaborando para assimilação de conceitos matemáticos, como por exemplo, funções, geometria, porcentagens e é elementar na construção e no amadurecimento de ideias. Se não for bem alicerçada, os alunos poderão encontrar dificuldades posteriores.

Pensando nisso, buscamos desenvolver nossa pesquisa, que tem como objetivo geral investigar a ação dos estudantes durante a interação com jogos educativos afim de compreender como eles aprendem álgebra por meio desses materiais.

Com os resultados obtidos, queremos contribuir com as aulas de matemática, aumentando a compreensão acerca das possíveis contribuições desses jogos para o ensino e a aprendizagem de álgebra.

Foi realizada uma busca no Google Acadêmico com o intuito de encontrar suporte teórico para sustentar nossa pesquisa e procuramos por artigos que relatavam sobre as dificuldades na aprendizagem de álgebra por alunos do $8^{\circ}$ do Ensino Fundamental. Para tanto, inserimos as seguintes palavras chaves: "dificuldades"; "aprendizagem de álgebra"; "ensino fundamental". Dentre as obras resultantes, escolhemos as ideias de Costa et al. (2016) e Costa (2018) pois são pesquisas mais recentes e em relação às outras, centralizam a abordagem na aprendizagem. Além destes, 
consideramos importante ressaltar o trabalho de Brum e Cury (2013) que faz uma análise dos erros nas soluções de questões que envolvem álgebra e já foi citado 7 vezes, deste modo compreendemos a relevância de seus resultados e, portanto, a significância para nossos estudos.

\section{Referencial Teórico}

Segundo Gil e Felicetti (2016, p. 20) "entende-se a álgebra como parte da Matemática que trabalha a generalização e abstração, representando quantidades através de símbolos", assim, para muitos estudantes é um conteúdo complexo devido sua abstração pois envolve a associação de letras e números.

A álgebra é importante não apenas no cotidiano escolar, mas também é utilizada em situações diárias fora da sala de aula. São várias as aplicações em diferentes áreas de conhecimento, tais como o cálculo de população de bactérias e dosagem de medicamentos, nas áreas de biologia e medicina, e também na programação de computadores com a representação de fórmulas (GIL; FELICETTI, 2016).

Podemos citar também o uso da álgebra em funções usadas no dia a dia, por exemplo, quanto será gasto na padaria para comprar determinada quantidade de pães, calcular o gasto estimado para uma festa com $x$ convidados, estimar o valor diário de combustível utilizado para estudar ou trabalhar, analisar condições oferecidas por diferentes planos de saúde para verificar o mais vantajoso, dentre outras aplicações.

Brum e Cury (2013) dizem que em meio aos avanços tecnológicos e o vasto campo de informações, tornou-se essencial a comunicação através de diferentes tipos de representação. Nesse contexto, percebemos a linguagem algébrica que "permite ao aluno representar e resolver situações por meio de expressões e equações, desenvolvendo seu raciocínio para solucionar problemas, dentro e fora da escola" (BRUM; CURY, 2013, p. 46).

No âmbito escolar, cabe destacar a notoriedade da álgebra na estrutura curricular: 
Para resolver uma equação, fatorar uma expressão algébrica ou fazer uma simplificação a fim de reduzir a expressão à algo mais simples, é preciso utilizar conhecimentos, técnicas e realizar manipulações algébricas, com diferentes graus de dificuldade, desde as mais simples às mais complexas (COSTA et al., 2016, p. 1).

A Base Nacional Comum Curricular faz o tratamento da álgebra como unidade temática e nos anos finais do Ensino Fundamental, por meio deste item,

[...]os alunos devem compreender os diferentes significados das variáveis numéricas em uma expressão, estabelecer uma generalização de uma propriedade, investigar a regularidade de uma sequência numérica, indicar um valor desconhecido em uma sentença algébrica e estabelecer a variação entre duas grandezas. É necessário, portanto, que os alunos estabeleçam conexões entre variável e função e entre incógnita e equação. (BRASIL, 2017, p. 271).

Com base nesses argumentos, nota-se o relevante papel da álgebra na base de ensino, já que contribui tanto para a formação estudantil quanto para a atuação de um indivíduo na sociedade, pois com tais habilidades desenvolvidas, como a capacidade de resolução de problemas, é mais preparado para lidar com situações cotidianas.

Apesar disso, cabe destacar os obstáculos encontradas na aprendizagem, é comum encontrarmos estudantes que apresentam dificuldades nos procedimentos algébricos. Em uma experiência das últimas autoras deste trabalho com turmas de $8^{\circ}$ ano, foi verificado que os alunos confundem algumas operações, por exemplo, na multiplicação entre $x$ e $2 x$, eles entendiam que o resultado seria $3 x$, quando na verdade o resultado $2 x^{2}$.

A pesquisa de Costa et al. (2016) traz considerações importantes, os autores buscaram verificar as principais dificuldades dos alunos de $8^{\circ}$ na aprendizagem desse conteúdo aplicando problemas de álgebra, alguns envolvendo o cálculo de perímetro e área. O estudo realizado em três escolas do Rio Grande do Sul relata que os discentes apresentam problemas de interpretação, que levava a resolução incorreta das questões. Além disso, os sujeitos não tinham compreensão dos conceitos envolvidos e demonstravam dificuldades em dominar técnicas algébricas elementares. 
Gil e Felicetti (2013) também se empenharam em pesquisar sobre as causas das dificuldades na aprendizagem de álgebra por alunos do $8^{\circ}$ ano, que refletiram também na interpretação dos problemas quando é exigido a tradução da linguagem natural para a simbólica, ou seja, os alunos não conseguem formalizar os problemas na linguagem matemática. Os autores constataram que as dificuldades com aritmética também desencadeiam esses problemas, 0 fato de não existir um pré-requisito na continuidade dos estudos faz com que os alunos iniciem as noções de álgebra com esses obstáculos.

O mesmo é dito por Booth (1995, apud BRUM; CURY 2013, p. 48), quando afirma que a álgebra "não está separada aritmética; na verdade, é, em muitos aspectos, a aritmética generalizada". Segundo ele, esta é a causa das dificuldades pois para compreender as relações na álgebra e necessário entender primeiro as relações no campo aritmético.

Brum e Cury (2013) ao apresentarem os resultados parciais de uma dissertação, buscaram analisar os erros cometidos por 23 alunos do $8^{\circ}$ do Ensino Fundamental, de uma escola pública em um município do Rio Grande do Sul, na resolução de questões de álgebra. Seus resultados também apontam que há erros na passagem da linguagem natural para a algébrica.

Diante dos fatos expostos, buscaremos investigar os fatores que dificultam a aprendizagem de álgebra e contribuir com uma proposta didática para o desenvolvimento desse conteúdo. Apresentamos abaixo a metodologia utilizada e como procedeu a análise dos resultados.

\section{Metodologia}

Bogdan e Binklen (1994) apontam que na pesquisa qualitativa os investigadores participam do ambiente de pesquisa portando equipamentos para os registros como, por exemplo, gravadores e blocos de anotações a fim de levantar elementos descritivos do ambiente e sujeitos pesquisados. A ênfase é dada no processo, ou seja, os caminhos que levam aos resultados, os dados são analisados de forma indutiva e buscando exprimir as causas de determinados problemas. Com base nessas implicações consideramos nossa pesquisa de caráter qualitativo. 
A pesquisa foi realizada em uma escola da rede pública municipal localizada na cidade de São Mateus - ES e a coleta de dados foi feita em três encontros de 90 minutos cada um. Ao todo, 12 alunos participaram, porém nem todos estiveram presentes em todos os encontros, ou seja, 6 alunos estiveram em 1 encontro, 5 alunos estiveram em 2 encontros e 1 aluno nos três encontros.

Para a análise dos dados, optamos por analisar apenas os dados dos estudantes que participaram de 2 ou mais encontros (6 estudantes), estes possuem idade entre 13 e 15 anos, sendo 4 meninas e 2 meninos.

Os sujeitos da pesquisa eram alunos do $8^{\circ}$ ano do Ensino Fundamental que frequentavam aulas de reforço de matemática no contra turno escolar, que era realizado no período vespertino, durante dois encontros semanais de 90 minutos cada um, por quase todo o ano letivo. Alguns dos sujeitos da pesquisa já tinham em algum momento reprovado em matemática e apresentavam dificuldades na disciplina.

Para a coleta dos dados foram aplicados: uma lista de exercíciosº ${ }^{2}$; um questionário ${ }^{3}$ feitas anotações durante a interação com dois jogos. A lista é composta por atividades do livro didático ${ }^{4}$ que os estudantes utilizam em suas aulas de matemática.

O questionário, adaptado de Machado (2018, p. 54) visa analisar a opinião dos alunos em relação a matemática e a álgebra, com perguntas abertas e fechadas, por exemplo: $\mathrm{O}$ que você entende por matemática? E álgebra? Você acha que a álgebra é útil no dia a dia? Além disso, foi dado um espaço para eles escreverem onde encontram suas dificuldades e facilidades.

O jogo "Eu tenho... Quem tem? ..." , adaptado de Moraes et. al (2004) é semelhante ao dominó, nele os alunos devem interligar 18 fichas contendo expressões algébricas. Pode ser executado com até 18 pessoas, onde cada

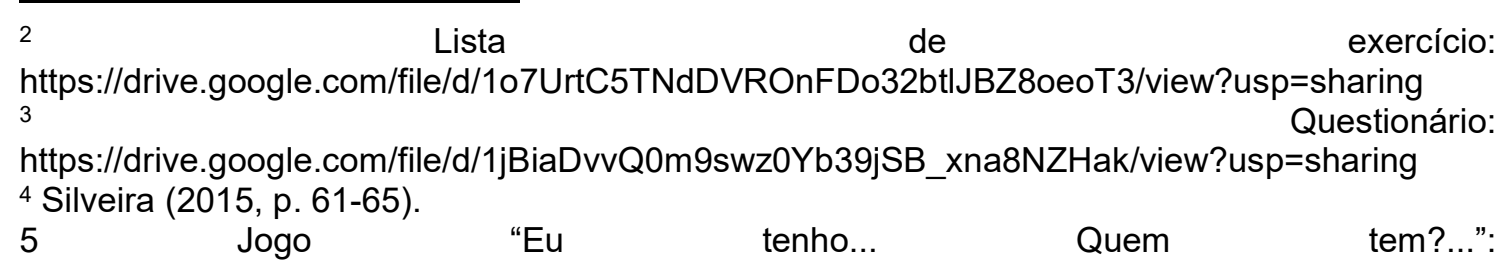
https://drive.google.com/file/d/1_EUqBQi_MIHEK01orWhNOPwLZOruscPW/view?usp=sharing. 
uma recebe uma ficha. Caso seja realizado em um grupo menor, cada pessoa recebe mais de uma ficha.

O jogo começa com a pessoa que possuir a ficha: "Eu tenho X. Quem tem o dobro do meu número?". Em seguida, joga a pessoa que tem a ficha: "Eu tenho 2x. Quem tem o meu número mais duas unidades?". Logo depois, joga a pessoa com a ficha: "Eu tenho $2 x+2$. Quem tem o meu número somado com $2 x-4$ ?", seguida pela ficha: "Eu tenho 4x - 2. Quem tem o meu número multiplicado por x?". Assim, segue o jogo até que a última ficha: "Eu tenho 0", seja lançada. Por exemplo:

Figura 01: Exemplo do jogo "Eu tenho... Quem tem?"

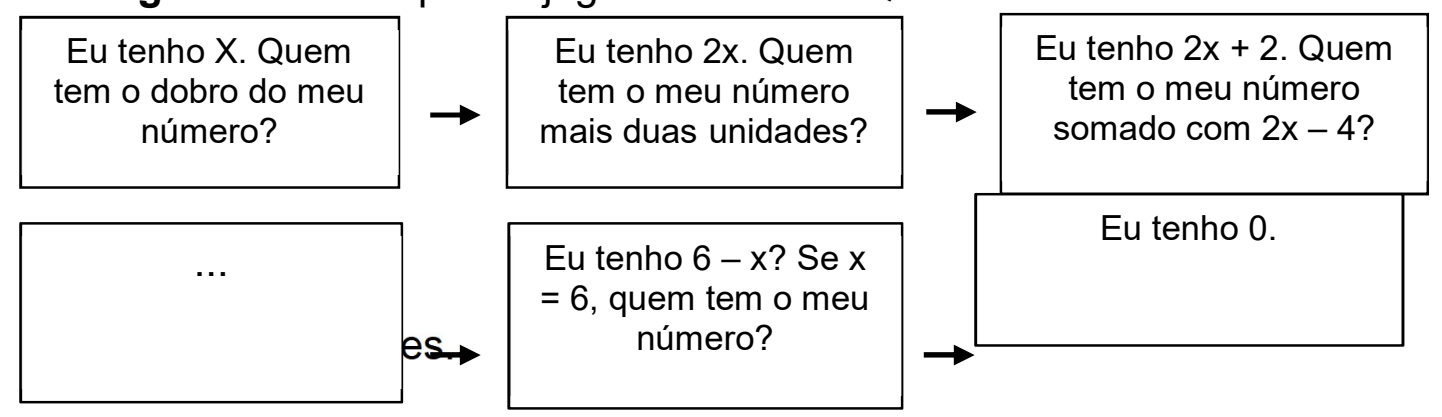

Para a produção do material foram necessárias folhas com as impressões das fichas, papel cartão e papel adesivo.

A segunda parte desse jogo foi uma atividade escrita ${ }^{6}$ em que os alunos, individualmente, se encarregaram de preencher os espaços vazios, de modo que as sentenças estivessem devidamente associadas, por exemplo:

Figura 02: "Eu tenho... Quem tem?..." - Segunda parte

$\begin{aligned} & \text { a) Eu tenho } 5 x+30 . \text { Quem tem a quinta parte do meu número? Eu tenho ___ } \\ & \text { tem }\end{aligned}$. Eu tenho $3 x+18$.

Fonte: Sá (2012) apud Santana e Sá (2011).

Para esta parte foram necessárias apenas folhas impressas com essa atividade.

6 Segunda parte do jogo "Eu tenho... Quem tem?...": https://drive.google.com/file/d/17Qobvk4RCIEVM_VE1Rm2UhWx0FIrj_bA/view?usp=sharing. 
O objetivo do jogo "Eu tenho... Quem tem? ..." é permitir aos alunos o contato com a álgebra de forma lúdica. Através dos desafios propostos por cada ficha, eles são levados a instigar o resultado, ou seja, qual peça se encaixa no jogo. Com isso, são trabalhadas operações de soma, subtração e multiplicação de polinômios despertando o pensamento algébrico.

O outro jogo aplicado foi o Algeplan, definido por Santos, Conceição e Paula (2018, p. 5) como "um material manipulativo utilizado para o ensino de soma, subtração, multiplicação e divisão de polinômios de grau no máximo dois, utilizando áreas de retângulos”. Pode ser praticado na forma concreta ou virtual (Figura 03).

Figura 03: Peças do Algeplan.
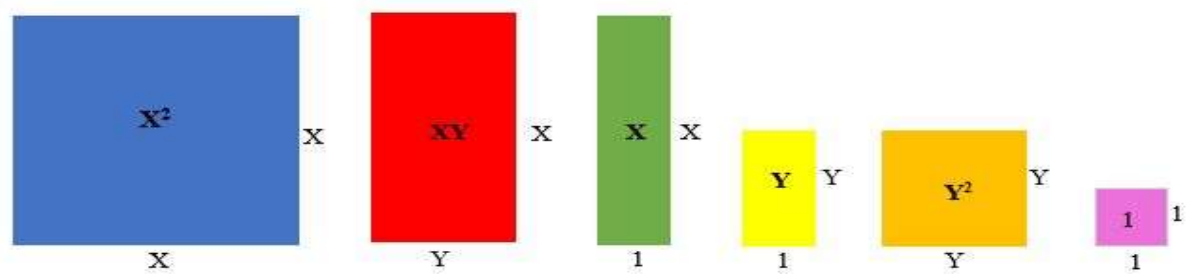

Fonte: Os autores

A distribuição é feita da seguinte forma: 4 quadrados de área $x^{2}, 4$ quadrados de área $y^{2}, 12$ quadrados de área 1,4 retângulos com áreas xy, 8 retângulos de áreas x e 8 retângulos de área y, totalizando 40 peças.

A turma foi separada em duplas e para cada uma delas foi entregue um kit contendo as peças do Algeplan e uma folha contendo as atividades solicitadas ${ }^{7}$. Por exemplo, na primeira questão, para um contato inicial com o jogo, foi pedido que as duplas representassem com o Algeplan a expressão $2 x^{2}+2 x y+3$. Eles deveriam remeter o seguinte:

7 
Figura 04: Expressão $2 x^{2}+2 x y+3$

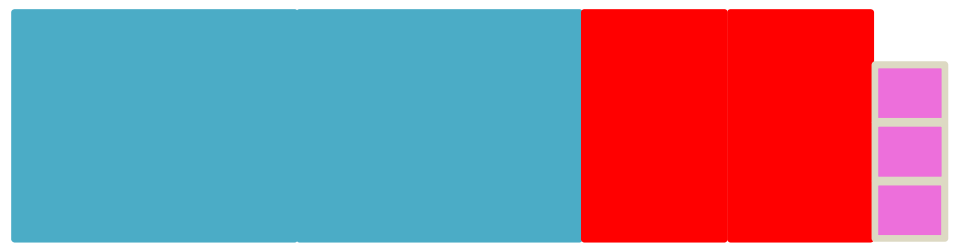

Fonte: Os autores

Mais adiante, na atividade envolvendo multiplicação, foi pedido que os alunos representassem um retângulo de área $(x+1)(x+2)$, que deveriam responder da seguinte forma:

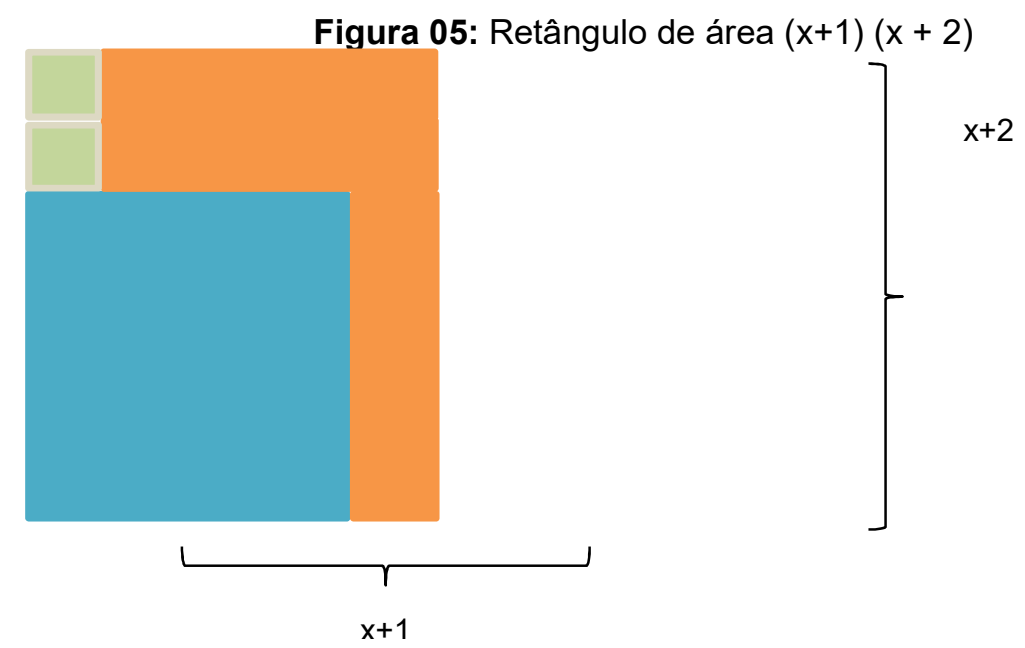

Fonte: Os autores

Notamos que ao simplificar o polinômio, as peças do jogo representam cada monômio da expressão, $x^{2}+3 x+2$ e as medidas dos lados são iguais aos fatores da multiplicação.

A outra proposta do exercício é que os alunos mediante uma figura já montada, diga qual o perímetro e área correspondente, de modo que relacionem operações com polinômios à geometria por meio de um material concreto, o que possibilita uma melhor visualização do que ocorre nas expressões algébricas até então abstratas. 


\section{Apresentação e Análise dos dados}

Os sujeitos desta pesquisa foram denominados, de forma fictícia, por A1, A2, A3, A4, A5 e A6.

No primeiro dia foi aplicado uma lista de exercícios do próprio livro didático e por meio de 3 questões buscamos identificar suas principais dificuldades em álgebra. Participaram deste momento os alunos A1, A2, A3, A4 e A5.

A primeira questão pedia que os alunos reduzissem os termos semelhantes de 5 expressões algébricas. Alguns deles, como a A1, após lerem o enunciado não sabiam exatamente o que era para ser feito perguntando como deveriam iniciar as questões. Explicamos, por meio de exemplos, que eles deveriam agrupar os termos semelhantes até que não fosse mais possível simplificar a expressão algébrica.

Ao acompanharmos o desenvolvimento dessa questão, observamos que alguns possuíam dificuldades com mudanças sinal (como dito pela aluna A5), ao retirarem algum monômio dos parênteses e quando somavam um número negativo com um positivo. Outra dúvida identificada foi da aluna A3 que ao resolver a questão $(3 x+2)(x-3)$ perguntou: "Essa é de vezes né?" Acreditamos que a dúvida se dá pelo fato de não ter o sinal de multiplicação visível na questão. A mesma aluna perguntou se 0 monômio $3 x^{3}$ era equivalente a $3^{3} x^{3}$ o que reflete um erro de conceituação em relação à potenciação, já que nesse caso apenas a variável x é elevada ao cubo.

Observamos também que alguns alunos esqueceram de somar os expoentes quando se tratava de uma multiplicação e em alguns casos perguntavam se isso era possível na soma dos termos que envolviam variáveis comuns, o que não é correto, sendo exato apenas na multiplicação.

$\mathrm{Na}$ segunda questão era necessário calcular o perímetro de uma figura somando os lados $(x+2)+(2 x+1)+(3 x+3)+(3 x / 2+1)$, o que resultaria no resultado $15 x / 2+7$. Vimos que a aluna $A 3$ estava em dúvida quanto ao cálculo do $\mathrm{mmc}$, perguntando se poderia fazê-lo de apenas um monômio, $3 \times / 2$, demonstrando dificuldades na adição de frações, que foi um erro comum a todos. Os alunos após calcularem o mmc, chegando na expressão $(2 x+4+4 x$ 
$+2+6 x+6+3 x+2) / 2$, eliminaram o denominador 2 , tal procedimento só é possível quando se trata de uma equação. Um exemplo desse erro é a resolução da aluna A5 a seguir.

Figura 06: Erro na adição de fração e cálculo do mmc da aluna A5

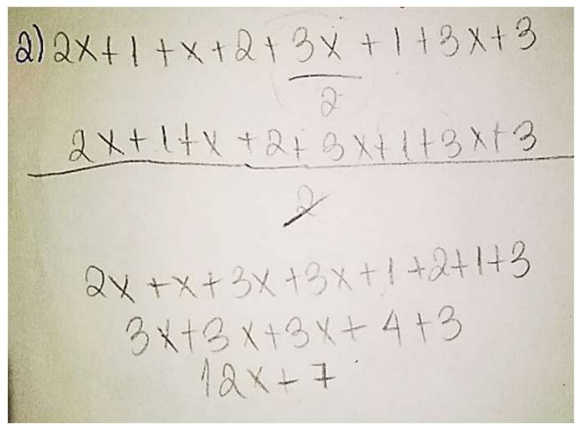

Fonte: Os autores

A terceira questão tinha como enunciado: "Qual é o polinômio que representa a área da região cinza da figura?".

Figura 07: Atividade 01, exercício 3

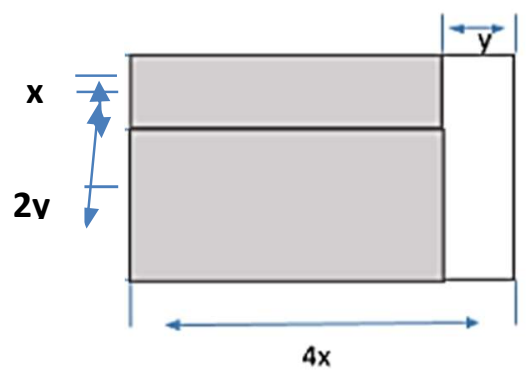

Fonte: Silveira (2015)

Primeiro os alunos deveriam montar a seguinte expressão: $(2 y+x)(4 x-y)$, onde cada fator da multiplicação representa um lado do retângulo (região cinza) e após resolverem chegariam no resultado $7 x y-2 y^{2}+4 x^{2}$. Aqui, notamos erros conceituais por parte das alunas A1 e A5 que calcularam o perímetro da figura ao invés de terem calculado a área e mesmo assim o fizeram de forma incorreta. Ambas dividiram a figura em dois retângulos, mas identificaram os lados incorretamente, como mostramos abaixo: 
Quadro 01: Resolução das estudantes A1 e A5 para a questão 03

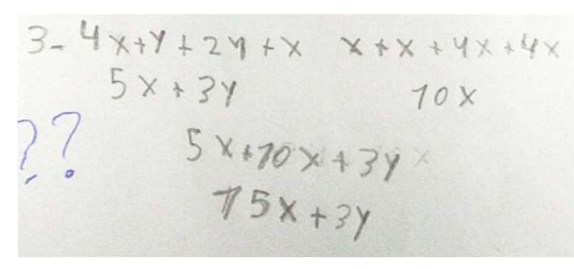

A1

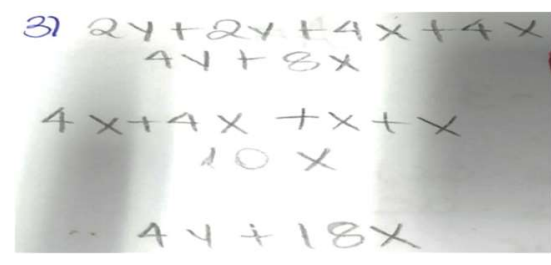

A5

Fonte: Os autores

A aluna A1 identificou um lado do primeiro retângulo como $4 x+y$, quando deveria ser $4 x-y$ e por ter dividido a figura em duas partes, o outro lado desse retângulo deveria ter dimensão $2 y$ e não $2 y+x$ (Quadro 01, (I)). Já a aluna A5 também identificou um dos lados como 4x quando deveria ser 4x-y (Quadro 01, (II)). Podemos dizer que as alunas não fizeram a interpretação correta do exercício.

O quadro abaixo apresenta os erros cometidos pelos alunos em cada questão da atividade do primeiro dia. A primeira coluna contém os erros, a segunda coluna mostra os alunos, e a terceira são a letra das questões correspondentes. Os erros estão em negrito para melhor localização.

Quadro 02: Análise de erros da primeira atividade

\begin{tabular}{|c|c|c|}
\hline Erros & Alunos & Letra \\
\hline \multicolumn{3}{|l|}{ Questão 1} \\
\hline $\begin{array}{c}\text { Troca de sinal } \\
\text { Ex: }-3 x^{2}+6 x^{2}=-3 x^{2}\end{array}$ & A2 e A5 & \multirow{2}{*}{ a } \\
\hline $\begin{array}{l}\text { Erro de cálculo } \\
\text { Ex: }-3-8=-12\end{array}$ & A3 & \\
\hline $\begin{array}{c}\text { Erro de cálculo } \\
\text { Ex: }+(5 b c+3 a b-a c)=5 b c-3 a b-a c \\
8 a b-7 b c+3 a c-5 b c+3 a b-a c=8 a b-3 a b-7 b c-5 b c+3 a c-a c\end{array}$ & A2 e A5 & b \\
\hline $\begin{array}{c}\text { Troca de sinal } \\
\text { Ex: }-\left(8 a b+5 a^{2}-7 b^{2}\right)=-8 a b+5 a^{2}-7 b^{2}=-8 a b+5 a^{2}-7 b^{2}\end{array}$ & A5 & c \\
\hline $\begin{array}{c}\text { Erro de cálculo } \\
\text { Ex: }(3 x+2)(x-3)=3 x^{2}-9 x+2 x-6=3 x-7 x-6\end{array}$ & A1 & d \\
\hline $\begin{array}{c}\text { Troca de sinal } \\
\text { Ex: }(-2 x+5)\left(6 x^{2}+4 x+3\right)=-12 x^{3}-8 x^{2}+6 x+30 x^{2}+20 x+15 \\
(-2 x+5)\left(6 x^{2}+4 x+3\right)=-12 x^{3}+8 x^{2}+6 x-30 x^{2}+20 x+15\end{array}$ & A2 e A5 & \multirow[t]{2}{*}{ e } \\
\hline $\begin{array}{l}\text { Erro de cálculo } \\
\text { Ex: }-6 x+20=-14 x\end{array}$ & A5 & \\
\hline \multicolumn{3}{|l|}{ Questão 2} \\
\hline $\begin{array}{c}\text { Adição de fração } \\
\text { Ex: } 2 x+1+x+2+3 x / 2+1+3 x+3=2 x+x+3 x / 2+3 x+1+2+1+3=\end{array}$ & \multicolumn{2}{|c|}{ Todos } \\
\hline
\end{tabular}




\begin{tabular}{|c|c|}
\hline$=(4 x+2 x+3 x+6 x) / 2+1+2+1+3=15 x+7$ & \\
\hline $\begin{array}{l}\text { Erro de cálculo } \\
\text { Ex: } \begin{array}{c}2 x+1+x+2+3 x / 2+1+3 x+3=(4 x+2 x+3 x+6 x) / 2+2+4+2+6= \\
8 x+4 x+6 x+12 x+2 x+4+2+6=-30 x+14\end{array}\end{array}$ & A2 \\
\hline $\begin{array}{c}\text { Cálculo do mmc } \\
\text { Ex: } 2 x+1+x+2+3 x / 2+1+3 x+3=(2 x+1+x+2+3 x+1+3 x+3) / 2\end{array}$ & A5 \\
\hline \multicolumn{2}{|l|}{ Questão 3} \\
\hline $\begin{array}{l}\text { Interpretação. Não identificou corretamente a base do retângulo. } \\
\text { Ex: base }=4 x+y \text { ou } 4 x \text {, deveria ser } 4 x-y \text {. }\end{array}$ & A1e A5 \\
\hline $\begin{array}{l}\text { Erro conceitual. Calcularam o perímetro e não a área como solicitado. } \\
\qquad \text { Ex: } 2 y+2 y+4 x+4 x=4 y+8 x, 4 x+4 x+x+x=10 x \\
\qquad 4 y+8 x+10=4 y+18 x \\
\text { obs: A aluna separou o retângulo em dois, porém além de identificar o } \\
\text { valor de um lado de forma errada, calculou o perímetro da figura. }\end{array}$ & A1 e A5 \\
\hline
\end{tabular}

Fonte: Os autores

O que se pode observar é que os erros mais comuns foram os de cálculo, refletindo falta de atenção por parte dos alunos quando resolviam as questões. Além disso a troca de sinais para alguns é uma dificuldade, isso se relaciona ao que foi dito por dito por Booth (1995, apud BRUM; CURY 2013, p. 48), em que é necessário primeiro compreender as relações aritméticas para que os conceitos algébricos sejam bem desenvolvidos.

O fato de todos os alunos errarem a adição de fração pode ser por não saberem a diferença entre uma expressão algébrica e uma equação, sendo necessário retomar esses conceitos.

Quantos os erros de interpretação, Costa et al. (2016), Gil e Felicetti (2013) e Brum e Cury (2013) também já apontaram em suas pesquisas. Em seus resultados foi constatado falha da interpretação levando a resolução incorreta dos problemas e dificuldade na transição da linguagem natural para algébrica. O que se pode observar é que os alunos quando perguntados sobre como calcular área e perímetro, respondiam de forma oral corretamente, porém ao fazerem os cálculos, não conseguiam identificar os lados de forma correta.

No segundo encontro participaram os alunos A2, A3, A4 e A6 e aplicamos o jogo "Eu tenho... Quem tem?...". Na interação dos alunos foi notada a dúvida em relação ao que é uma expressão e uma equação, ao perguntarem, logo na primeira carta ("Eu tenho x. Quem tem o dobro do meu número?"), se era necessário igualar a conta, refletindo novamente a confusão 
entre uma expressão algébrica e uma equação. Nesse caso, os alunos deveriam apenas identificar que 2x é o dobro de $x$.

Outros problemas identificados foram na utilização ou não dos parênteses e quando aplicar a propriedade distributiva, chamada por eles de "chuveirinho". Por exemplo, na $3^{\circ}$ carta do jogo pedia o seguinte: "Eu tenho $2 x$ + 2. Quem tem o meu número somado com $2 x-4$ ?". O grupo composto pelas alunas $A 1$ e $A 2$ teve dúvidas sobre a utilização do parêntese em $2 x-4$ e se para resolver a conta utilizaria a distribuição. Embora o parêntese nesse caso não altere o resultado, sua utilização é importante para fazer as devidas manipulações aritméticas, já a propriedade distributiva é caraterística da multiplicação. O mesmo foi percebido quando resolviam o problema da $4^{\circ}$ carta (“Eu tenho 4x -2. Quem tem o meu número multiplicado por x?”), aqui surgiu expressões do tipo: "Tem que colocar parênteses?", "Agora é o chuveirinho né?".

Ainda percebemos problemas quanto aos expoentes dos polinômios, por exemplo, na $7^{\circ}$ carta, ao se depararem com a conta $-x^{3}+2 x^{3}$, perguntavam se era para somar os expoentes, demonstrando ainda dificuldades na redução das expressões, já que essa propriedade é aplicada na multiplicação de polinômios. Esse tipo de problema seguiu durante todo o desenvolvimento do jogo, sempre os alunos não se sentiam confiantes quanto a utilização dos parênteses e aplicação da propriedade distributiva, mas sempre nos preocupávamos em explicar e sanar essa dúvida.

$\mathrm{Na}$ segunda parte do jogo, aplicamos uma atividade onde cada aluno preenchia as lacunas em branco de modo que as sentenças ficassem interligadas corretamente. Foi notado erro de interpretação de modo que, logo na primeira sentença, foi necessário ajudar aos alunos $A 2, A 3$ e $A 6$, pois não conseguiram fazer sozinhos o que se pedia.

No último exercício desse dia (letra d), os alunos demonstraram dificuldades em sua interpretação. Nessa atividade era necessário pensar de maneira inversa, "de trás para frente". O único valor que o exercício apresentava era o número 70 e caberia o raciocínio de pensar qual número que multiplicado por $x$ (sendo $x=5$ ) se chega a esse resultado, a resposta correta 
seria o número 14 e o resultado apresentado deveria ser 14x. A partir daí se pensaria qual a metade desse número para que se encaixasse na primeira sentença, como mostramos abaixo.

Figura 08: Segunda atividade, letra d.

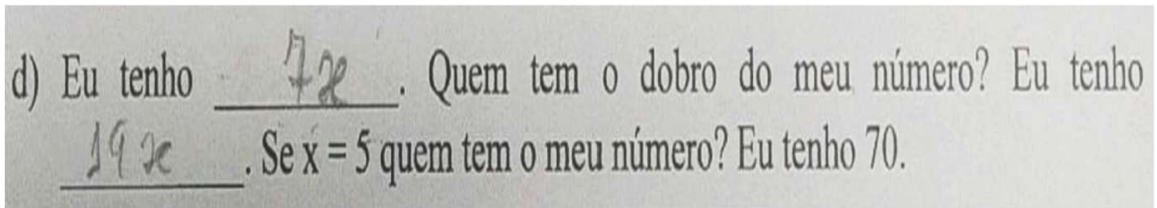

Fonte: Os autores

$\mathrm{Na}$ aplicação dessa atividade, notamos maiores dificuldades nessa questão por todos, inclusive o aluno A4 que teve um bom desenvolvimento nos dias anteriores também não conseguiu fazer sozinho, sendo necessário mostrar o caminho para que fosse possível a sua resolução. $O$ fato se deve pela questão exigir um pouco mais de raciocínio.

O aluno A6 no decorrer dessa atividade demonstrou dificuldades em toda as questões, sendo necessário acompanhá-lo nas resoluções, o principal problema apresentado foi quanto a interpretação.

De um modo geral listamos as dificuldades apresentadas pelos alunos.

Quadro 03: Análise de erros da segunda atividade

\begin{tabular}{|c|c|c|}
\hline Erros & Aluno & Letra \\
\cline { 1 - 2 } Interpretação. Foi prestado auxílio para interpretar a questão & A2, A3 e A6 & a \\
\hline Em branco & A6 & c \\
\hline Em branco & A6 & d \\
\hline Interpretação. Foi prestado auxílio para interpretar a questão & A2, A3 e A4 &
\end{tabular}

Fonte: Os autores

O fato das atividades envolverem bastante raciocínio lógico e interpretação pode ser um fator que dificultou o desenvolvimento dos alunos. Interpretar as atividades foi uma dificuldade acentuada do grupo pesquisado, retomando novamente aos resultados de Costa et al. (2016), Gil e Felicetti (2013) e Brum e Cury (2013).

No terceiro dia de aplicação participaram os alunos A1, A4, A5 e A6, formando as seguintes duplas: alunas $A 1$ e $A 5$ e alunos A4 e A6. Inicialmente começamos falando sobre o Algeplan e a relação que se pode ter entre 
geometria e álgebra por meio desse jogo. Os alunos ressaltaram que nunca tiveram contato com essa ferramenta.

Então explicamos o funcionamento e resolvemos a primeira questão da atividade, letra a do número 1 juntamente com eles, que tratava de representar as expressões algébricas por meio do Algeplan. Falamos que ao resolver deveriam observar se era necessário simplificar a expressão e assim começaram a resolução sozinhos.

As letras a $\left(2 x^{2}+2 x y+3\right)$ e $b\left(x^{2}+5 x y+2-3 x y\right)$ foram resolvidas por ambas as duplas corretamente, porém antes a aluna $\mathrm{A} 5$ teve dúvidas na letra $b$, se era necessário simplificar ou não a expressão. Falamos que existiam termos que poderiam ser agrupados e após isso, mostraram o seguinte resultado:

Figura 09: Representação correta da expressão $x^{2}+5 x y+2$ - 3xy com Algeplan

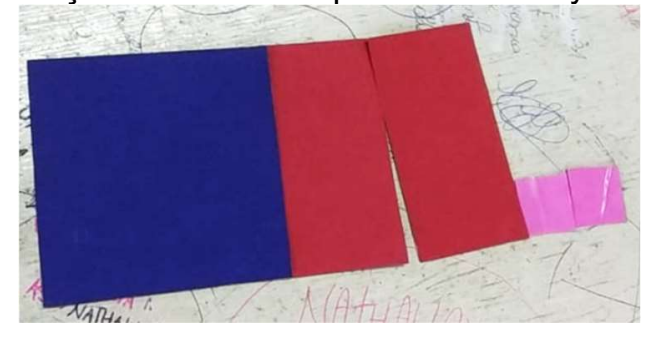

Fonte: Os autores

Os alunos A4 e A6 também resolveram de forma correta, sem a necessidade de prestarmos algum auxílio. Os mesmos também executaram corretamente a letra $\mathrm{c}$ do exercício que pedia a representação da expressão $\mathrm{x}^{2}$ $-3+3 y^{2}+5$.

Na segunda atividade, os alunos deveriam, a partir de uma multiplicação entre polinômios, representar geometricamente um dado retângulo. Fizemos a primeira questão como exemplo para os alunos compreenderem como se dava a montagem das figuras, assim, deram sequência da resolução da segunda questão, letra b. Pedimos para se atentarem ao fato de que cada monômio que compõe a expressão reduzida indica cada figura a ser utilizada.

As alunas $\mathrm{A} 1$ e $\mathrm{A} 5$ fizeram o tratamento algébrico corretamente, porém na passagem para o Algeplan tiveram dificuldade sobre quais peças utilizariam, apresentando o seguinte: 
Figura 10: Representação incorreta do retângulo x $(x+3)$ no Algeplan.

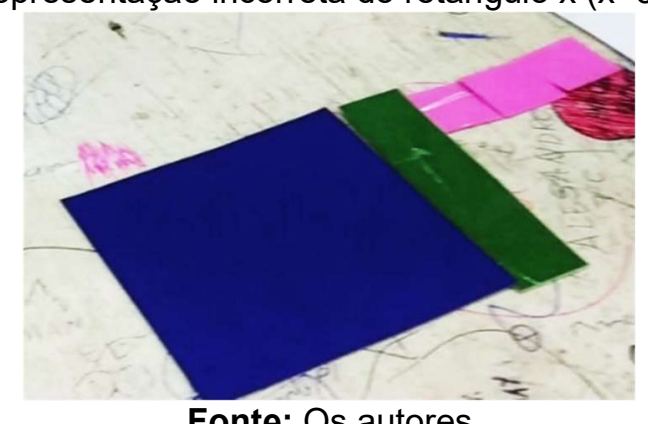

Nota-se que a figura solicitada foi um retângulo, que não foi o apresentado pelas alunas. Então orientamos novamente as alunas a reduzirem a expressão e com base no resultado identificar as peças a serem utilizadas de modo a formar o retângulo solicitado. Após a correção mostraram o seguinte:

Figura 11: Representação correta do retângulo $x(x+3)$ no Algeplan

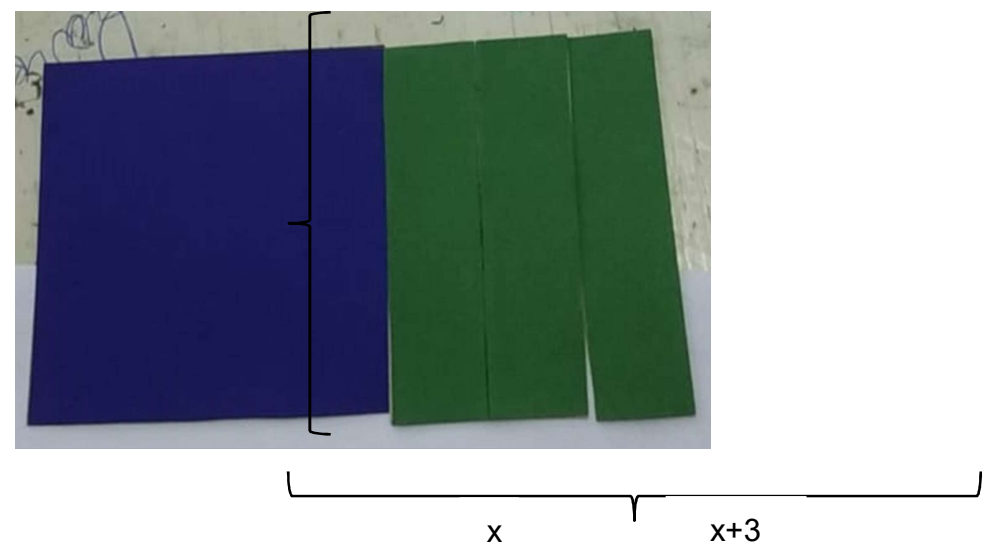

Fonte: Os autores

Analisamos juntamente com elas o resultado mostrado de forma a visualizarem nas figuras seus lados, no caso da expressão $x(x+3)$, o lado x e 0 lado $\mathrm{x}+3$ estavam devidamente representados.

O aluno A4 teve dúvida na resolução dessa mesma questão, orientamos a reduzir primeiramente a expressão, identificar as peças que compõe o retângulo e montar a figura.

$\mathrm{Na}$ letra c, as alunas A1 e A5 apresentaram erro tanto algébrico quanto na montagem das figuras. Ao resolver a expressão $(x+y)(x+y)$ onde cada parêntese indica o lado de um quadrado, apresentaram $x^{2}+y^{2}+2 x y^{2}$ como 
resposta. Nesse caso há um erro em $2 x y^{2}$, que deveria ser $2 x y$, as alunas somaram os expoentes de y, fato que só pode ocorrer na multiplicação.

Após orientações, refizeram a questão de forma correta, porém expressaram no Algeplan de forma errada. Como mostra abaixo:

Figura 12: Representação incorreta do quadrado $(x+y)(x+y)$ no Algeplan

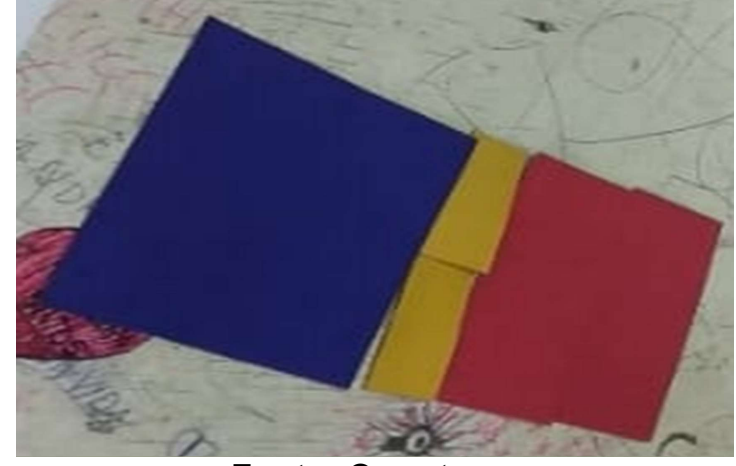

Fonte: Os autores

Mostramos a elas que na figura apresenta não existe os lados $(x+y)$ $(\mathrm{x}+\mathrm{y})$ que corresponde ao quadrado solicitado. Analisando com o resultado algébrico $\left(x^{2}+y^{2}+2 x y\right)$, mostramos que na figura montada não há o monômio $y^{2}$ e que também colocaram peças que não eram necessárias, como o y (retângulo amarelo). Após isso, montaram a figura corretamente:

Figura 13: Representação correta do quadrado $(x+y)(x+y)$ no Algeplan

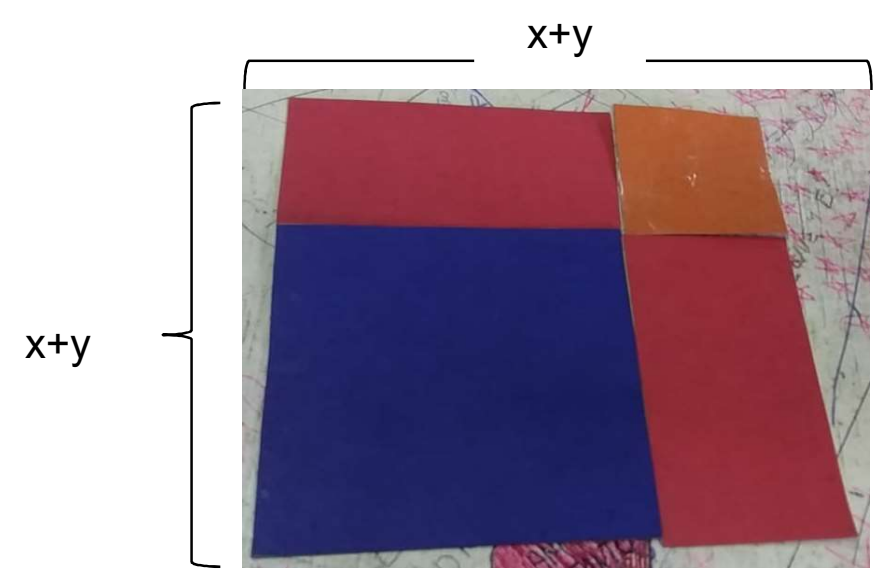

Fonte: Os autores 
No último exercício, os alunos deveriam, a partir de uma figura já montada dizer quais polinômios representam a área e perímetro de cada uma. As alunas A1 e A5 chegaram corretamente na expressão $(y+1)(y+y)$ para o cálculo de área e ao calcular o perímetro a aluna A5 disse: "Eu acho que é a mesma coisa, só que tem que somar". Sendo assim, apresentaram o seguinte:

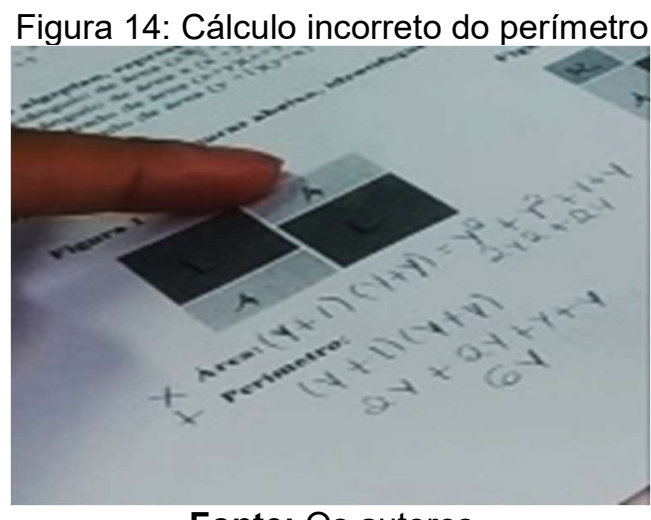

Fonte: Os autores

Ao calcularem o perímetro as alunas aplicaram a propriedade distributiva e ao mesmo tempo somaram, além disso consideraram apenas dois lados, sendo que o perímetro é a soma de todos os lados, não colocando o sinal de adição. Ainda nessa questão as alunas calcularam que $1+y=y$, remetendo a um resultado que seria da multiplicação.

Resolvendo a letra b desse exercício, as alunas A1 e A5 ao calcularam a área cometeram um erro de cálculo quando fizeram que $1 \times 1=2$ e novamente no cálculo de perímetro, as alunas consideraram apenas dois lados da figura e armaram a conta na forma de multiplicação, sendo necessário orientá-las quanto ao cálculo correto.

Nesta atividade foi possível perceber mais precisamente os erros conceituais de perímetro e área. As alunas A1 e A5 apresentaram dificuldades em identificar os lados de um quadrado e executaram cálculos incorretos do perímetro, confundindo em alguns casos com o cálculo de área.

A passagem da linguagem natural para a algébrica ou da algébrica para a geométrica e vice-versa foi uma dificuldade apresentada pelas alunas. Gil e 
Felicetti (2013) também enfatizaram isso em seus resultados mostrando que os alunos têm dificuldade de transitarem entre essas formas de representação.

A pesquisa de Costa et al. (2016) e Brum e Cury (2013) também mostram as dificuldades dos estudantes quanto ao cálculo de área a perímetro, sendo assim, há a necessidade que esses conceitos sejam bem desenvolvidos no processo ensino aprendizagem.

Procuramos sempre sanar as dúvidas dos alunos de modo que chegassem na representação correta dos polinômios. Enfatizamos as alunas A1 e A5 pois foram as que mais demonstraram problemas nessas atividades. $\mathrm{Na}$ dupla dos alunos $\mathrm{A} 4$ e A6, notamos bom desempenho deste primeiro, e percebemos que ele sempre dava orientações a sua dupla.

Os dados obtidos no questionário refletiram informações relevantes, participaram desse momento os alunos A1, A4, A5 e A6. Quando perguntados sobre o que eles entendem por matemática, no geral as respostas obtidas são: cálculo, concentração e raciocínio. O aluno A6 afirmou o seguinte: "A matemática é uma disciplina muito boa para raciocinar".

Os alunos falaram da importância da disciplina, onde dois deles a associam ao futuro e dois deles afirmam sua utilidade no dia a dia. Na pergunta "Você acha importante estudar essa disciplina? Por que?", o aluno A4 respondeu: "Sim, matemática é um ensino fundamental para se entender o mundo hoje em dia".

Na pergunta "Você gosta de estudar matemática?", o mesmo aluno respondeu: "Mais ou menos A maioria das matérias são bem complicadas e algumas eu só vou usar em um momento bem específico". É importante ressaltar que o aluno A4 apresentou facilidade em todas as questões, no entanto ainda considera a matemática complicada. Já os alunos A5 e A6 afirmam gostarem muito da disciplina pois possibilita aprender coisas novas.

Dentre os conteúdos que mais gostam de estudar, os alunos responderam o seguinte:

A1: "polinômios";

A4: "formulas, porcentagens e estatística";

A5: "álgebra e um pouco de triângulos"; 
A6: "gostei de estudar a técnica de chuveirinho".

O entendimento de álgebra pelos alunos é curioso, a aluna A1 entende álgebra por retas, já os alunos A4 e A5 entendem como letras e números. O aluno A6 diz que só entende algumas coisas.

Para o aluno A1 estudar álgebra é difícil, pois há certa confusão, o aluno A4 diz que é difícil por ser uma questão de lógica e regras. Os alunos A5 e A6 dizem ser legal estudar o conteúdo, o interessante é que esses alunos foram os que mais apresentaram dificuldades.

Sobre representar algebricamente uma situação, os alunos A5 e A6 acham legal, porém a aluna $\mathrm{A} 1$ acha difícil e o aluno A6 considera chato.

Uma reflexão importante foi quando a maioria dos alunos afirmaram que a álgebra é mais ou menos útil no dia a dia. O aluno A4 disse: "É algo que eu usaria raramente no meu trabalho e não no dia a dia". A aluna A5 afirmou: "Porque usamos mais conta de números racionais, inteiros e decimais". Tais afirmações mostram que há a necessidade contextualizar o conteúdo a realidade dos estudantes para que compreendem sua aplicabilidade e importância.

Após as atividades realizadas pedimos para os alunos expressarem 0 grau de dificuldade quanto a aprendizagem de álgebra. Os alunos A1 e A4 afirmaram ser fácil, já os alunos A5 e A6 afirmam ser médio.

Nota-se pelo questionário que os alunos não conseguem visualizar a aplicabilidade da álgebra no dia a dia. Essa ideia já foi abordada por Portes e Alves (2014, p. 2) ao afirmarem que os alunos não veem um significado prático para se estudar álgebra além da dificuldade de associar letras e números.

\section{Considerações finais}

Ao longo da coleta de dados identificamos alguns problemas, quanto ao desenvolvimento de questões algébricas. Desde a primeira atividade aplicada notamos dificuldade de alguns alunos quanto a interpretação. Apesar de operações com polinômios serem parte de um conteúdo já estudado por eles, ao realizarem atividades desse tipo, alguns deles precisaram de ajuda para 
interpretar os enunciados, por exemplo, não sabiam o que significava a expressão "reduza os termos semelhantes".

Também foi verificado que alguns alunos não tinham o pleno entendimento da aplicação de algumas propriedades, ou seja, em casos onde a expressão envolvia apenas adição alguns procuravam somar os expoentes de termos semelhantes, fato que só é possível na multiplicação.

Além disso, foi possível verificar dificuldades quanto a aritmética onde alguns estudantes erraram manipulações elementares, na retirada de algum termo dos parênteses quando envolviam sinais diferentes ou até mesmo na soma de um número positivo com outro negativo. Na interação com o primeiro jogo, esses problemas foram ainda mais evidentes por meio das dúvidas apresentadas, por exemplo, perguntavam se deveriam igualar expressões, se era possível somar expoentes na adição de monômios, qual sinal resultante de uma operação com número negativo e positivo.

O jogo "Eu tenho... Quem tem? ..." além de envolver conhecimento algébrico, envolvia também o raciocínio, logo a interpretação, que é um fator não muito desenvolvido pelos alunos apesar da importância na aprendizagem de matemática.

Ao envolver geometria e álgebra no jogo Algeplan, notamos que alguns alunos confundem o conceito de área e perímetro. As alunas A1 e A5 apresentaram erros conceituais, como calcular o perímetro somando apenas dois lados de um retângulo e aplicando a propriedade distributiva erroneamente.

Ainda notamos a dificuldade dos alunos em transitarem entre as diversas formas de representar um polinômio, seja na passagem da linguagem natural para a algébrica ou da linguagem algébrica para a geométrica, refletindo o problema da interpretação.

A ludicidade promoveu um despertar do interesse dos alunos na execução de tarefas, como as propostas ao longo da coleta de dados. As atividades permitiram aos alunos o contato com formas diferentes de executarem operações com polinômios, intensificando o raciocínio lógico que pode ser uma forma de potencializar o pensamento cognitivo. 
A interação com os jogos funcionou como uma ação investigativa mostrando as dificuldades de conceitualização, de perímetro e área por exemplo, aritmética, na troca de sinais, e interpretação, que foram obstáculos para a potencialização da aprendizagem por meio de jogos. Por isso, promover pesquisas que buscam entender essas dificuldades auxiliarão no pleno desenvolvimento da álgebra.

Além disso, buscar metodologias que promovam a contextualização dos conceitos algébricos é de suma importância pois assim os alunos atribuem significado ao que é estudado, passando a atuar de forma participativa, fator importante no processo de construção do indivíduo.

\section{Referências}

BOGDAN, R. C.; BIKLEN, S. K. Investigação qualitativa em educação. Uma introdução à teoria e aos métodos. Porto - Portugal. Porto Editora, 1994.

BOOTH, L. Dificuldades das crianças que se iniciam em Álgebra. In: COXFORD, A. F.; SHULTE, A. P. As ideias da Álgebra. São Paulo, Atual Editora, 1995. p. 23-37.

BRASIL. Base Nacional Comum Curricular (BNCC). Brasília: MEC. 2017. Disponível em: $<$ http://basenacionalcomum.mec.gov.br/images/BNCC_El_EF_110518_versaofi nal_site.pdf> Acessado em 07/10/2019.

BRUM, L. D.; CURY, H. N. Análise de erros em soluções de questões de álgebra: uma pesquisa com alunos do ensino fundamental. Revista de ensino de ciências e matemática - RenCiMa. v. 4, n. 1, p. 45-62, 2013.

COSTA, D. C.. Resolução de problemas no ensino e na aprendizagem da álgebra. Castanhal, 2018.

COSTA et. al. Investigando as dificuldades apresentadas em álgebra por alunos do oitavo ano do Ensino Fundamental. Revista Destaques Acadêmicos, Lajeado, v. 8, n. 4, p. 159-176, 2016.

GIL, K. H. Reflexões sobre as dificuldades dos alunos na aprendizagem de álgebra. Porto Alegre, 2008. Disponível em: http://repositorio.pucrs.br/dspace/bitstream/10923/2962/1/000401324Texto\%2BCompleto-0.pdf. Acesso em 09/09/2019.

GIL, K. H. FELICETTI, V, L. Reflexões sobre as dificuldades apresentadas na aprendizagem da álgebra por estudantes da $7^{a}$ série. Revista Sergipana de Matemática e Educação Matemática - Revisem. Sergipe, v, 1, n. 1, p. 19 35, 2016. 
MACHADO, T. F. Reflexões sobre a aprendizagem de álgebra no Ensino Fundamental. Rio Grande, 2018.

MORAES, D. C. et al. Um tratamento lúdico para o ensino e aprendizagem de álgebra. In: VIII Encontro Nacional de Educação Matemática, 2004, Recife. Anais, 2004. Disponível em: Acessado em 01/09/2018.

PORTES, D. S.; ALVES, G. M. O estudo das operações de polinômios com material concreto. Os desafios da escola pública paranaense na perspectiva do professor PDE. Versão Online, ISBN 978-85-8015-080-3, Cadernos PDE. Paraná, 2014. Disponível em: $<$ http://www.diaadiaeducacao.pr.gov.br/portals/cadernospde/pdebusca/produco es_pde/2014/2014_utfpr_mat_artigo_dirlei_aparecida_de_siqueira_portes.pdf $>$. Acessado em 09/09/2019.

SÁ, L. C. Uma análise do projeto "algebrincando na sétima série". 2012. Disponível em $<$ http://proativa.virtual.ufc.br/sipemat2012/papers/681/submission/director/681.p $\mathrm{df}>$. Acessado em 01/09/2018.

SANTANA, D. F.; SÁ, L. C. Da linguagem em prosa para a linguagem algébrica: uma experiência com o jogo "Eu tenho... Quem tem...?. In: II Encontro Estadual do PIBID, 2011, Vitória. Anais, 2011.

SANTOS, N. M. S.; CONCEIÇÃO, E. B. O.; PAULA, J. de S. Articulação entre geometria e álgebra com uso do algeplan: Um relato sobre aplicações de atividades do pibid-matemática/dma/ufs. $11^{\circ}$ Encontro Internacional de Formação de Professores. 12 Fórum Permanente Internacional de Inovação Educacional. $4^{\circ}$ Encontro Estadual da Associação Nacional pela Formação de Professores Seção Sergipe. 2018. Disponível em $<$ https://eventos.set.edu.br/index.php/enfope/article/view/8796/3995>.

Acessado em 30/09/2019.

SILVEIRA, E. Matemática: Compreensão e prática. 3. ed. São Paulo: Moderna, 2015.

VELOSO, D. S.; FERREIRA, A. C. Uma reflexão sobre as dificuldades dos alunos que se iniciam no estudo da álgebra. Revista da Educação Matemática da UFOP. Ouro Preto, V. 1, p.59-65, 2011. Disponível em: https://www.repositorio.ufop.br/bitstream/123456789/1292/1/EVENTO_Reflex\% C3\%A3oDificuldadesAlunos.pdf. Acesso em 09/09/2019.

\section{Sobre os Autores}

\section{Valdinei Cezar Cardoso}

Valdinei.cardoso@ufes.br

Professor da Universidade Federal do Espírito Santo (Ufes) - Departamento de Matemática aplicada. 


\section{Caroline Alves Santiago}

calvessantiago@gmail.com

Licencianda em matemática (Universidade Federal do Espírito Santo - Ufes).

Roberta dos Santos Ribeiro

robertaribbeiro@hotmail.com

Licencianda em matemática (Universidade Federal do Espírito Santo - Ufes). 